\title{
A method of cooling capacity enhancement of ceiling panel
}

\author{
Janusz Wojtkowiak ${ }^{1, *}$, and Lukasz Amanowicz ${ }^{1}$ \\ ${ }^{1}$ Institute of Environmental Engineering, Poznan University of Technology, Poland
}

\begin{abstract}
The cooling energy demand in the buildings is quite large nowadays and it will increase rapidly in the near future. Therefore, capacity of existing cooling devices must be increased. In this paper surface corrugation as a method of capacity enhancement of ceiling panels is theoretically investigated. A subject of the analysis is the effect of corrugation length $L$ and corrugation angle $\beta$ on the panel's cooling capacity. It is shown that in the typical conditions the cooling power of the panel with modified surface can achieve even $153 \mathrm{~W} / \mathrm{m}^{2}$ and it is about up to 2.5 times higher than the power of a reference panel with flat surface.
\end{abstract}

\section{Introduction}

Currently, cooling of the buildings represents a considerable fraction of the total energy consumption. It is predicted that between 2010 and 2050 the cooling energy demand of the residential and commercial buildings will increase by 7.5 and 2.8 times, respectively [1]. For this reason, more efficient new cooling devices ought to be developed or an efficiency of the selected existing devices has to be improved. The ceiling cooling panels are devices with many advantages. They provide the good thermal comfort, high indoor air quality and low energy consumption [2]. Unfortunately, they have one serious disadvantage namely small cooling power per unit of their surface. The radiant power of cooling panels can be increased by covering their surface with a paint of high emissivity. An increase in convective power can be achieved both by increasing surface area and by increasing the convective heat transfer coefficient. Many researches focus on increasing cooling performance of ceiling panels. Miriel et al. [3] studied cooling capacity of ceiling panel system build of copper pipes with aluminium fins. Jeong and Mumma [4] investigated the cooling enhancement by mixed convection in mechanically ventilated spaces of ceiling panel. Fredriksson [5] focused attention on the air flow structure generated by cooling ceiling beam. Kosonen [6] studied the effect of heat load location and intensity on air flow pattern with passive chilled beam. Lun Zhang et al. [7] investigated thermal capacity of a suspended metal ceiling radiant panel with inclined aluminium fins. An idea of corrugated surface as a method of increasing convective heat transfer was suggested by Al-Arabi and El-Rafaee [8]. Bobaru and Rachakonda [9] applied a special algorithm to optimize such modified surfaces. In this paper the panels with corrugated surfaces are investigated

\footnotetext{
*Corresponding author: janusz.wojtkowiak@put.poznan.pl
} 
theoretically. The cooling capacities of such panels are compared with capacity of reference ceiling panel having flat horizontal surface.

Table 1. Nomenclature.

\begin{tabular}{|c|c|}
\hline $\mathrm{Gr}_{L}[-]$ & Grashof number \\
\hline$h\left[\mathrm{~W} /\left(\mathrm{m}^{2} \mathrm{~K}\right)\right]$ & total heat transfer coefficient \\
\hline$L[\mathrm{~m}]$ & corrugation length \\
\hline $\mathrm{Nu}_{\mathrm{L}}[-]$ & Nusselt number \\
\hline $\operatorname{Pr}[-]$ & Prandtl number \\
\hline$q\left[\mathrm{~W} / \mathrm{m}^{2}\right]$ & total cooling capacity \\
\hline$q_{c}\left[\mathrm{~W} / \mathrm{m}^{2}\right]$ & convective cooling capacity \\
\hline$q_{c o r}\left[\mathrm{~W} / \mathrm{m}^{2}\right]$ & total cooling capacity of corrugated surface \\
\hline$q_{f f l a t}\left[\mathrm{~W} / \mathrm{m}^{2}\right]$ & total cooling capacity of flat surface \\
\hline$q_{r}\left[\mathrm{~W} / \mathrm{m}^{2}\right]$ & radiant cooling capacity \\
\hline$T_{\text {air }}[\mathrm{K}]$ & air temperature \\
\hline$T_{\text {ref }}[\mathrm{K}]$ & reference temperature \\
\hline$T_{\mathrm{s}}[\mathrm{K}]$ & panel surface temperature \\
\hline$T_{w}[\mathrm{~K}]$ & wall temperature \\
\hline$\beta[\mathrm{deg}]$ & corrugation angle \\
\hline$\varepsilon[-]$ & emissivity \\
\hline$\sigma_{o}\left[\mathrm{~W} /\left(\mathrm{m}^{2} \mathrm{~K}\right)\right]$ & Stefan-Boltzmann constant $\left(=5.67 \cdot 10^{8}\right)$ \\
\hline$\lambda_{\text {air }}[\mathrm{W} /(\mathrm{mK})]$ & air thermal conductivity \\
\hline
\end{tabular}

\section{Investigated surfaces and aim of the work}

The simplest triangular corrugation is studied (Fig. 1). Each panel, irrespective of the corrugation length $L$ and corrugation angle $\beta$, occupies the same rectangular area $A \times B$. The aim of the work is to investigate the effect of $L$ and $\beta$ values on the panel cooling capacity. There is one working surface of the ceiling panel - the bottom surface, or in other words, cold surface facing downward. It is assumed that the top surface of the panel is perfectly insulated - adiabatic.

a)

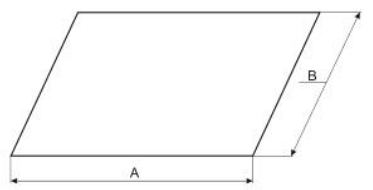

b)

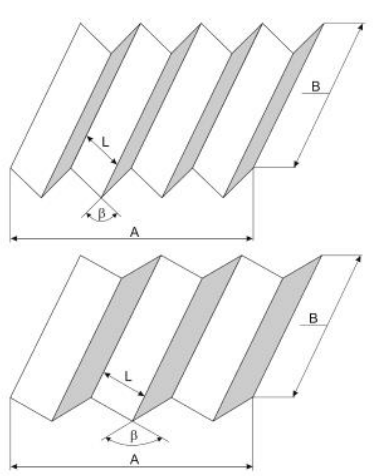

c)

Fig. 1. Geometry of analysed surfaces; a) flat surface, b) and c) corrugated surfaces of different $L$ and $\beta$. 


\section{Calculation method}

An influence of corrugation on the panel radiant power is small. Therefore, for each surface shown in Fig. 1, the radiant component was calculated using the same formula:

$$
q_{r}=\varepsilon \sigma_{0}\left(T_{w}{ }^{4}-T_{s}^{4}\right)
$$

Free convection at the panel surface was assumed. The convective component of the cooling capacity was calculated as:

$$
q_{c}=h\left(T_{a i r}-T_{s}\right)
$$

where:

$$
h=\left(\mathrm{Nu}_{L} \cdot \lambda_{L}\right) / L
$$

The Nusselt number was calculated by means of experimentally obtained formulas [8]:

For the laminar region:

$$
2.5 \cdot 10^{4}<\left(\mathrm{Gr}_{L} \operatorname{Pr}\right) \leq\left(\mathrm{Gr}_{L} \mathrm{Pr}\right)_{c r}, \mathrm{Nu}_{L}=C_{l}\left(\mathrm{Gr}_{L} \operatorname{Pr}\right)^{m}
$$

For the turbulent region:

$$
\left(\mathrm{Gr}_{L} \operatorname{Pr}\right)_{c r}<\left(\mathrm{Gr}_{L} \operatorname{Pr}\right) \leq 2 \cdot 10^{7}, \mathrm{Nu}_{L}=C_{2}\left(\mathrm{Gr}_{L} \operatorname{Pr}\right)^{1 / 3}
$$

where:

$$
m=0.148 \cdot \sin (\beta / 2)+0.187
$$

$$
\begin{gathered}
\left(\mathrm{Gr}_{L} \mathrm{Pr}\right)_{c r}=15.8 \cdot 10^{5}-14.4 \cdot 10^{5} \cdot \sin (\beta / 2) \\
C_{1}=[0.46 / \sin (\beta / 2)]-0.32 \\
C_{2}=0.09+0.054 / \sin (\beta / 2) \\
T_{r e f}=\left(T_{\text {air }}+T_{s}\right) / 2
\end{gathered}
$$

For an angle $\beta=180^{\circ}$ both equations (4) and (5) give approximately the same value of $\mathrm{Nu}$ valid for a semi-infinite flat plate surface and turbulent region:

$$
\mathrm{Nu}_{L}=0.144 \cdot\left(\mathrm{Gr}_{L} \mathrm{Pr}\right)^{1 / 3}
$$

The total cooling capacity was calculated as:

$$
q=q_{r}+q_{c}
$$




\section{Calculation results}

The calculations were conducted for the following data: $\varepsilon=0.95, T_{\text {air }}=T_{w}=298 \mathrm{~K}\left(25^{\circ} \mathrm{C}\right)$ and $T_{s}=291 \mathrm{~K}\left(18^{\circ} \mathrm{C}\right)$. The results of calculation are shown in $3 \mathrm{D}$ and $2 \mathrm{D}$ coordinate systems in Figs. 2 and 3, respectively. In Table 2 the values of total heat transfer coefficient are presented. Table 3 contains a comparison between cooling capacities of corrugated and flat surfaces: $q_{c o r} / q_{f l a t}$. In Table 4 the share of convection in total heat transfer capacity $q_{c} / q$ is shown.
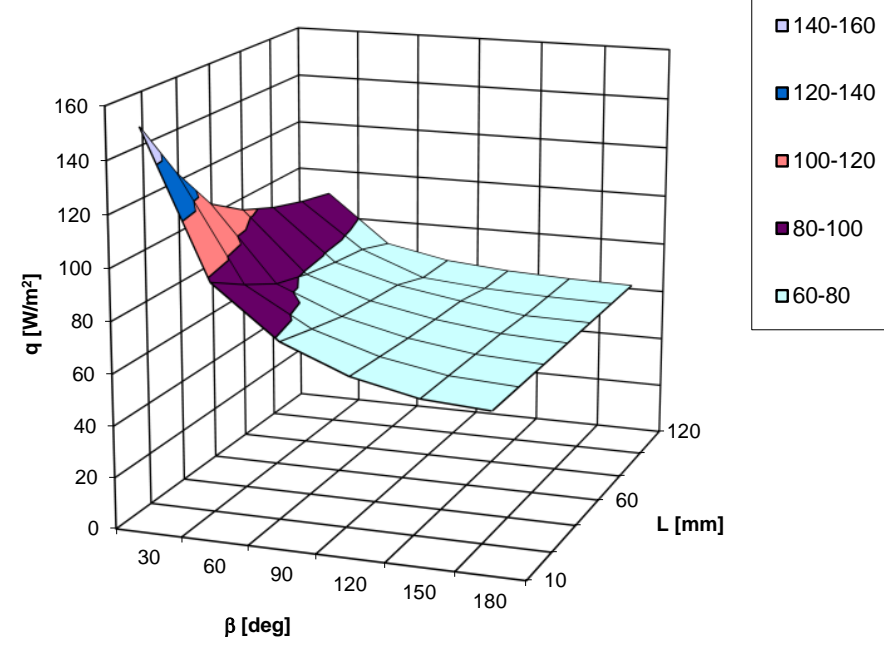

Fig. 2. Total heat transfer capacity $q$ as a function of corrugation length $L$ and angle $\beta$.

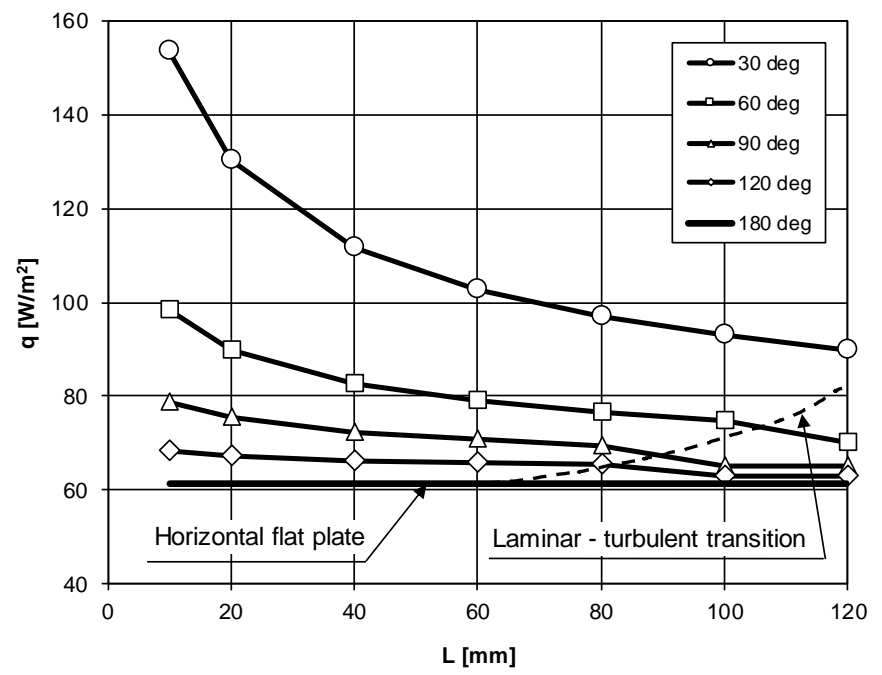

Fig. 3. Total heat transfer capacity $q$ as a function of corrugation length $L$ for various angles $\beta$. 
Table 2. Total heat transfer coefficient $h\left[\mathrm{~W} /\left(\mathrm{m}^{2} \mathrm{~K}\right)\right]$ for various corrugation lengths $L[\mathrm{~mm}]$ and angles $\beta$ [deg].

\begin{tabular}{|c|c|c|c|c|c|c|}
\hline $\boldsymbol{L}$ & $\boldsymbol{3 0}$ & $\mathbf{6 0}$ & $\mathbf{9 0}$ & $\mathbf{1 2 0}$ & $\mathbf{1 5 0}$ & $\mathbf{1 8 0}$ \\
\hline 10 & 21.9 & 14.0 & 11.3 & 9.8 & 9.0 & 8.8 \\
\hline 20 & 18.6 & 12.9 & 10.8 & 9.6 & 9.0 & 8.8 \\
\hline 40 & 16.0 & 11.8 & 10,3 & 9,5 & 8.9 & 8.8 \\
\hline 60 & 14.7 & 11.3 & 10.1 & 9.4 & 8.9 & 8.8 \\
\hline 80 & 13.9 & 10.9 & 9.9 & 9.3 & 8.8 & 8.8 \\
\hline 100 & 13.3 & 10.7 & 9.3 & 9.0 & 8.8 & 8.8 \\
\hline 120 & 12.8 & 10.0 & 9.3 & 9,0 & 8.8 & 8.8 \\
\hline
\end{tabular}

Table 3. Comparison of corrugated surface and flat surface cooling capacities $q_{\text {cor }} q_{\text {flat }} ; L[\mathrm{~mm}], \beta[\mathrm{deg}]$.

\begin{tabular}{|c|c|c|c|c|c|c|}
\hline $\boldsymbol{\beta}$ & $\mathbf{3 0}$ & $\mathbf{6 0}$ & $\mathbf{9 0}$ & $\mathbf{1 2 0}$ & $\mathbf{1 5 0}$ & $\mathbf{1 8 0}$ \\
\hline 10 & 2.50 & 1.60 & 1.28 & 1.12 & 1.03 & 1 \\
\hline 20 & 2.13 & 1.47 & 1.23 & 1.10 & 1.02 & 1 \\
\hline 40 & 1.82 & 1.35 & 1.18 & 1.08 & 1.02 & 1 \\
\hline 60 & 1.68 & 1.29 & 1.15 & 1.07 & 1.02 & 1 \\
\hline 80 & 1.58 & 1.25 & 1.13 & 1.07 & 1.01 & 1 \\
\hline 100 & 1.52 & 1.22 & 1.06 & 1.03 & 1.01 & 1 \\
\hline 120 & 1.47 & 1.15 & 1.06 & 1.03 & 1.01 & 1 \\
\hline
\end{tabular}

Table 4. Convection share in total heat transfer capacity $q_{c} / q ; L[\mathrm{~mm}], \beta[\mathrm{deg}]$.

\begin{tabular}{|c|c|c|c|c|c|c|}
\hline $\boldsymbol{L}$ & $\boldsymbol{3 0}$ & $\mathbf{6 0}$ & $\mathbf{9 0}$ & $\mathbf{1 2 0}$ & $\mathbf{1 5 0}$ & $\mathbf{1 8 0}$ \\
\hline 10 & 0.75 & 0.61 & 0.51 & 0.44 & 0.39 & 0.37 \\
\hline 20 & 0.70 & 0.57 & 0.49 & 0.43 & 0.39 & 0.37 \\
\hline 40 & 0.66 & 0.53 & 0.47 & 0.42 & 0.39 & 0.37 \\
\hline 60 & 0.63 & 0.51 & 0.46 & 0.41 & 0.38 & 0.37 \\
\hline 80 & 0.60 & 0.50 & 0.45 & 0.41 & 0.38 & 0.37 \\
\hline 100 & 0.59 & 0.49 & 0.41 & 0.39 & 0.38 & 0.37 \\
\hline 120 & 0.57 & 0.45 & 0.41 & 0.39 & 0.38 & 0.37 \\
\hline
\end{tabular}

\section{Discussion and conclusions}

The obtained results show that the cooling capacity of the panel with corrugated surface can be significantly larger in comparison with panel of flat surface. Each panel of corrugated surface has larger working area than panel with flat surface (Fig. 1). The cooling power increases as the corrugation length and corrugation angle decreases (Figs. 2 and 3). The smaller corrugation length the thinner the boundary layer and consequently the larger the heat transfer coefficient. For smaller corrugation angles the cooled air is removed easier from the corrugated surface than from the surface with larger angles. As a result, heat transfer is more effective.

Summing up the physical interpretation of the regularities shown in Figs. 2 and 3, it can be stated that there are three factors that cause increase of the cooling power of the corrugated surface: 1) larger working area, 2) smaller thickness of the boundary layer and 3) more intense air flow. 
As it can be seen in Figs. 2 and 3, the highest cooling power amounted to $q=153.4 \mathrm{~W} / \mathrm{m}^{2}$ was obtained for short $(L=10 \mathrm{~mm})$ and sharply formed $\left(\beta=30^{\circ}\right)$ corrugations. The above power is 2.5 times higher (Table 3 ) than the power of the reference flat surface: $q=61.3 \mathrm{~W} / \mathrm{m}^{2}$. For these two extreme cases, the values of the total heat transfer coefficient are $21.9 \mathrm{~W} /\left(\mathrm{m}^{2} \mathrm{~K}\right)$ for corrugated and $8.8 \mathrm{~W} /\left(\mathrm{m}^{2} \mathrm{~K}\right)$ for flat surfaces (Table 2). In general, the corrugation angle has larger influence on the cooling power than the corrugation length.

In spite of large emissivity $(\varepsilon=0.95)$ for small $L$ and $\beta$ values the convective heat transfer is dominant (Table 4). For $L=10 \mathrm{~mm}$ and $\beta=30^{\circ}$ the convective component is $75 \%$ of total cooling power. As $L$ and $\beta$ increase, the convective component decreases, and for the flat surface $\left(\beta=180^{\circ}\right)$ it has the smallest value of $37 \%$.

To summarize briefly, the following main conclusions can be drawn:

- corrugation can be an efficient method of cooling capacity enhancement of ceiling panels,

- the cooling capacity of the panel of corrugated surface can be up to 2.5 times larger than capacity of the reference panel having a flat surface,

- for typical conditions $\left(\varepsilon=0.95, T_{\text {air }}=T_{w}=25^{\circ} \mathrm{C}\right.$ and $\left.T_{s}=18^{\circ} \mathrm{C}\right)$, the cooling capacity of the panel with $L=10 \mathrm{~mm}$ and $\beta=30^{\circ}$ is $153 \mathrm{~W} / \mathrm{m}^{2}$ while for the panel of flat surface it is $61 \mathrm{~W} / \mathrm{m}^{2}$ only.

\section{References}

1. M. Santamouris, Energ. Buildings 128, 617-638 (2016)

2. S. B. Riffat, X. Zhao, P.S. Doherty, International Journal of Energy Research 28, 3, 257-286 (2004)

3. J. Miriel, L. Serres, A. Trombe, Appl. Therm. Eng. 22, 16, 1861-1873 (2002)

4. J. W. Jeong, S. A. Mumma, Appl. Therm. Eng. 23, 18, 2293-2306 (2003)

5. J. Fredriksson, M. Sandberg, B. Moshfegh, Building and Environment 36, 7, 891-899 (2001)

6. R. Kosonen, P. Saarinen, H. Koskela, A. Hole, Energ. Buildings 42, 1, 34-42 (2010)

7. L. Zhang, X.-H. Liu, Y. Jiang, Energ. Buildings 62, 522-529 (2013)

8. M. Al-Arabi, M. M. El-Rafaee, Int. J. Heat Mass Tran. 21, 357-359 (1978)

9. F. Bobaru, S. Rachakonda, Int. J. Heat Mass Tran. 47, 4953-4966 (2004) 